\title{
Cytokine Storm and Immunomodulation in COVID-19
}

\author{
Pradeep Rangappa 1
}

\begin{abstract}
COVID-19 has become a major pandemic in recent times. The exact pathophysiology and understanding of cytokine storm and immunomodulation are evolving. Various cytokines have been implicated in the pathophysiology of COVID-19. Immunosuppressant immunomodulators like steroids, canakinumab, anakinra, tocilizumab, sarilumab, baricitinib, ruxolitinib, bevacizumab, and itolizumab have been tried. Immunostimulant immunomodulators like interferons (IFNs) and Mycobacterium w (Mw) have also been repurposed. Considering the role of multiple cytokines implicated in COVID-19, molecules working on the majority of the targets, may hold a promising future prospect.

Keywords: COVID-19, Cytokine release syndrome, Cytokine storm, Mycobacterium w, Steroids, Tocilizumab.

Indian Journal of Critical Care Medicine (2021): 10.5005/jp-journals-10071-24029
\end{abstract}

\section{INTRODUCTION}

Novel coronavirus, also known as severe acute respiratory syndrome coronavirus-2 (SARS-CoV-2) which is the primary cause of COVID-19, has posed an enormous burden on healthcare and economics worldwide. ${ }^{1}$

The disease pattern of COVID-19 is highly variable which can range from asymptomatic infection to mild upper respiratory tract infection in the majority of the patients. However, some patients have severe symptoms in the form of pneumonia and other extrapulmonary complications that require admission in intensive care unit (ICU). Before symptom onset, viral shedding appears to begin 2-3 days earlier. From symptom onset, the infectivity diminishes drastically after 10 days. However, among survivors, the virus can be detected for an average of up to 37 days. $^{2}$

Despite more than 300 active clinical trials underway, the search continues for a potential treatment option. ${ }^{3}$ However, recently, the Indian regulatory agency has approved remdesivir and itolizumab in hospitalized COVID-19 patients for emergency use. Despite that, there is an ongoing search for an effective immunomodulator against COVID-19.

Various theories on immune evasion that is the process by which viruses avoid and antagonize the immune response of their host have been discussed. Favorable immune evasion of SARS-CoV-2 is possible in individuals with compromised ability to produce efficient immune responses that include elderly people and patients with immunodeficiency. Other factors like a high viral load may overcome the barriers of the immune responses. Both innate and adaptive immunity can be involved in the later stage of the disease if viruses escape control and inhibit IFN-1 resulting in a cytopathic effect. ${ }^{4}$

\section{Pathophysiology}

Though not properly defined, but cytokine storm involves an exaggerated immune response characterized by the release of multiple mediators in the form of proinflammatory and antiinflammatory cytokines. These mediators play an important role to impart an efficient innate immune response that can lead to the clearance of infectious agents. However, recent literature calls out for relooking of terminology of cytokine storm and its relevance
Department of Critical Care Medicine, Columbia Asia, Bengaluru, Karnataka, India

Corresponding Author: Pradeep Rangappa, Department of Critical Care Medicine, Columbia Asia, Bengaluru, Karnataka, India, e-mail: pratikclear@gmail.com

How to cite this article: Rangappa P. Cytokine Storm and Immunomodulation in COVID-19. Indian J Crit Care Med 2021;25(11): 1288-1291.

Source of support: Nil

Conflict of interest: None

to COVID-19. The plasma levels of IL- 6 which were reported in the patients with cytokine release syndrome in pre-COVID-19 era were significantly higher. ${ }^{5}$

World is learning every day about COVID-19 and recent literature has warranted more studies before we conclude anything on cytokine storm in COVID-19. Usually, the levels of cytokines are lower in COVID-19 in comparison with other causes of acute respiratory distress syndrome (ARDS). Hence, clarity of both innate and adaptive immune responses would be required before jumping to further concrete conclusions. Early interventions for modulating both innate and adaptive immune responses during COVID-19 infection may help to prevent a severe form of the disease. This may give a hint at developing therapeutic strategies, which will act on multiple pathways of immune response to prevent any severe impact due to COVID-19. ${ }^{6}$

- Role of spike S protein in cytokine storm: Cytokine storm is responsible for suffering and deaths seen in COVID-19. It is due to the induction of innate immune response by spike $S$ protein of SARS-COV-2 virus. It follows the contact of spike S protein with a receptor on immune cells called Toll-like receptor 4 (TLR4). Cytokine storm is uncontrolled hyperimmune response. It indicates that controlling immune response through TLR4 modulation can be of use.

- Toll-like receptors in innate immune response and cytokine storm: The TLRs are key components of innate immune system that can detect the infection to trigger an efficient immune

(c) The Author(s). 2021 Open Access This article is distributed under the terms of the Creative Commons Attribution 4.0 International License (https://creativecommons org/licenses/by-nc/4.0/), which permits unrestricted use, distribution, and non-commercial reproduction in any medium, provided you give appropriate credit to the original author(s) and the source, provide a link to the Creative Commons license, and indicate if changes were made. The Creative Commons Public Domain Dedication waiver (http://creativecommons.org/publicdomain/zero/1.0/) applies to the data made available in this article, unless otherwise stated. 
response. TLR family comprise 10 different members that play a crucial role in clearing infections. ${ }^{8}$ Literature suggests that TLR4, TLR7, and TLR8 are recognized by enveloped proteins and SsRNA viruses. ${ }^{9}$

- Role of p38 MAPK pathway in cytokine storm: p38 mitogenactivated protein kinase (MAPK) pathway is a key for release of IL-6. This is responsible for damaging the organs like lung and myocardium. Direct activation of p38 can be induced by SARS-CoV-2. This suggests that targeting of p38 may therefore be a good therapeutic strategy against COVID-19.10

Upregulation of P53 signaling pathway and different genes involved in apoptosis has been observed in peripheral blood cells that in turn can lead to lymphopenia which is seen commonly in COVID-19 patients. ${ }^{11,12}$ Hence, MAPK modulator and hence $\mathrm{p} 38$ downregulator may hold a promising therapeutic option in the future.

\section{Mechanisms of Action of Immunomodulatory Agents Currently Undergoing Clinical Development \\ Overview of Immunomodulatory Agents}

They may be broadly categorized into immunosuppressant immunomodulators and immunostimulant immunomodulators.

\section{Immunosuppressant Immunomodulators}

\section{Steroids}

Recently, RECOVERY trial results have revealed that the administration of dexamethasone in patients with COVID-19 who required a respiratory support, resulted in the greater mortality benefit. It exerts its effect via mineralocorticoid receptor binding in the context of SARS-CoV-2-induced dysregulation of the reninangiotensin system. ${ }^{13}$ However, we cannot apply the same benefit to other viral respiratory diseases that usually have a different clinical course as compared to COVID-19. ${ }^{13}$

\section{Canakinumab}

COVID-19 has been found to trigger the inflammasome and the release of interleukin-1 $\beta$. Canakinumab works by neutralization of $1 \beta$ signaling, resulting in suppression of inflammation. A study done in 10 hospitalized adult patients with COVID-19 and bilateral pneumonia found that it was well tolerated and effective in terms of clinical improvement. ${ }^{14}$ However, sample size and the nonrandomized nature of the study were the main limitations of the study. ${ }^{14}$

\section{Anakinra}

It has been postulated that COVID-19 can induce the production of proinflammatory and anti-inflammatory cytokines including interleukin-1. With this background anakinra, which is a recombinant IL-1 receptor antagonist was evaluated in 52 patients with severe forms of COVID-19. The dosage regimen included $100 \mathrm{mg}$ via subcutaneously route twice daily for 3 days, followed by $100 \mathrm{mg}$ daily for 7 days. ${ }^{15}$ It was well tolerated and found effective in terms of clinical improvement, mortality reduction, and oxygen requirement. The main limitations of the study were use of historical controls and differences among historical group in terms of sample size and confounding variables. ${ }^{15}$

\section{Tocilizumab and Sarilumab}

It is known so far that COVID-19 infection results in a production of IL- 6 from respiratory epithelial cells. Tocilizumab is an IL-6 inhibitor, has been evaluated in multiple randomized, doubleblind, placebo-controlled clinical trials to evaluate the safety and efficacy along with a standard of care against placebo plus standard of care in hospitalized adult patients with severe COVID-19 pneumonia. Another IL- 6 inhibitor, sarilumab, is also undergoing a large randomized multicenter, phase $2 / 3$ trial which is going to enroll up to 400 patients. ${ }^{16,17}$ Due to the correlation of increased IL- 6 levels in SARS-CoV-2, there is a great interest in repurposing of anti-IL- 6 agents for the management of COVID-19 patients, particularly in the advanced disease stage. A recent observational study of 154 patients with critically ill COVID-19 illness requiring mechanical ventilation found that tocilizumab was associated with a $45 \%$ reduction in the mortality. However, the frequency of superinfection was almost double in tocilizumab arm (54 vs $26 \%$ ). This suggests that close monitoring for superinfection is required. ${ }^{18}$ Recently, largest randomized clinical trial of tocilizumab, COVACTA trial failed to show benefits in terms of clinical improvement and mortality benefits in critically ill COVID-19 patients. ${ }^{19}$

\section{Baricitinib and Ruxolitinib}

Inhibition of IL- 6 via intracellular transduction pathway is another way of blocking action of IL-6. Both baricitinib and ruxolitinib are acting via inhibiting the JAK $1 / 2$ pathway. Baricitinib, a selective and powerful JAK-STAT signaling inhibitor, has been found to be effective against COVID-19 by artificial intelligence algorithm. ${ }^{20}$ It is currently being evaluated in a large phase 3 trial (BARI-COVID) with a dose of $4 \mathrm{mg} /$ day orally in mild-to-moderate COVID-19 infection. ${ }^{21}$

\section{Bevacizumab}

Vascular endothelial growth factor (VEGF) is a known inducer of vascular permeability which can lead to severe consequences in the lung ranging from edema to progressive lung disease. There are reports indicating the increased levels of VEGF in COVID-19. With this background, bevacizumab is currently under evaluation in an open label clinical trial in COVID-19 patients with pleural effusion. ${ }^{21}$

\section{Itolizumab}

It is a humanized recombinant anti-CD6 monoclonal antibody (MAb) which is already approved for psoriasis in India. Recently, the Indian regulator has granted its approval for emergency use in critically ill COVID-19 patients. ${ }^{22}$

\section{Immunostimulants Immunomodulators \\ Interferons}

During viral infection, type 1 IFNs are among the first cytokines produced which promote both innate and adaptive immunity. IFNs are key regulators for enhancing the immune system due to their antiviral, antiproliferative, and immunomodulatory activities. Early success has been detected with IFN treatment in different viral infections like the Middle East respiratory syndrome (MERS), SARS, human coronavirus 229E, and avian infectious bronchitis virus (IBV). The combination of IFN- $\alpha 2 a$ or IFN- $\alpha 2 b$ plus ritonavir resulted in significantly improved survival after 
14 days of treatment. Based on this, further safety and efficacy should be evaluated in combination with other antiviral drugs. ${ }^{23}$ A recent phase 2 trial evaluated the safety and efficacy of inhaled nebulized IFN- $\beta 1$ a for the treatment of SARS-CoV- 2 infection. Patients, who received inhaled nebulized IFN- $\beta 1 a$, had greater odds of improvement and recovered more rapidly from SARSCoV-2 infection as compared to placebo. However, small sample size differences in baseline parameters in both groups were the main limitations of the study. ${ }^{24}$

\section{Mycobacterium w}

Mycobacterium $\mathrm{w}(\mathrm{Mw})$ is a known immunomodulator. It is a nonpathogenic, saprophytic organism. Mw is a potent TLR2 agonist ${ }^{25,26}$ and a poly TLR antagonist $(4,5,7,9)$. It is a downregulator of $\mathrm{p} 38$ which is responsible for the production of various cytokines like IL-2, IL-6, TNF- $\alpha$, and IL-1b. ${ }^{27}$

The Mw is a potent inducer of Th1 response. ${ }^{28-30} \mathrm{Mw}$ given intradermally would result in an increased number of stimulated macrophages. ${ }^{31}$ These activated macrophages are responsible for the viral load clearance. It was also observed with SARS CoV infection that the function of dendritic cells was impaired. ${ }^{32} \mathrm{Mw}$ is known to induce potent activation of the dendritic cells by its TLR2 agonistic property, which further helps in curbing the viral infection. ${ }^{33}$ Moreover, Mw is known to clear intracellular pathogens like viruses, Mycobacterium tuberculosis on its own or when added to approved therapies. ${ }^{34-38}$ Induction of Th1 response results in the production of INF- $\gamma$. INF- $\gamma$ is known to reduce the expression of angiotensin-converting enzyme 2 which is essential for the entry of corona virus into the cell. ${ }^{39} \mathrm{Mw}$ is an antagonist of TLR4 receptor which would result in the inhibition of downstream cytokine production pathway and decreased production of various cytokines.

In spite of being a pure potent Th1 response enhancer, it is found to be safe in healthy humans as well as in those suffering from various diseases including immunocompromised individuals. It is known for its capacity to clear the infective organism from the body in preclinical as well as clinical studies. In the clinical trials conducted, Mw leads to early clinical recovery in most of the organ dysfunction including renal, respiratory, multisystem organ failure, and early improvement of SOFA score. ${ }^{40}$ These effects shown by $\mathrm{Mw}$ may be beneficial to those critical patients who are admitted in ICU with COVID-19 and associated complications. Mw is approved by DCGI in critical indications like sepsis and is devoid of the systemic adverse effects such as QT prolongation, torsades de pointes, hepatitis, acute pancreatitis, and anaphylaxis seen in the other current repurposed candidates being evaluated for COVID-19. ${ }^{41}$

A recent case series published from India has found that the C-reactive protein (CRP) levels improved gradually, and all the patients could be successfully managed without the need for mechanical ventilation after receiving $\mathrm{Mw}$ intradermally. Moreover, Mw did not cause any adverse events, similar to its previous experience in patients with severe sepsis. ${ }^{42}$ it is currently being evaluated in mild-to-moderate and critically ill patients of COVID-19.

\section{SUMMARY}

Cytokine storm may be misleading in COVID-19 ARDS due to differences in the levels of IL- 6 seen in COVID-19 vs chimeric antigen receptor T-cell (CART) therapies given earlier. Considering the role of multiple cytokines implicated in COVID-19, holistic approach in the management of COVID-19, molecules working on the majority of the targets, which are implicated in immune pathophysiology of COVID-19, may hold a promising future prospect.

\section{ORCID}

Pradeep Rangappa • https://orcid.org/0000-0002-2187-8950

\section{References}

1. Colaneri M, Bogliolo L, Valsecchi P, Sacchi P, Zuccaro V, Brandolino F, et al. Tocilizumab for treatment of severe COVID- 19 patients: preliminary results from SMAtteo COvid19 REgistry (SMACORE). Microorganisms 2020;8(5):695. DOI: 10.3390/ microorganisms8050695.

2. Matricardi PM, Dal Negro RW, Nisini R. The first, holistic immunological model of COVID-19: implications for prevention, diagnosis, and public health measures. Pediatr Allergy Immunol 2020;31(5):454-470. DOI: 10.1111/pai.13271.

3. Sanders JM, Monogue ML, Jodlowski TZ, Cutrell JB. Pharmacologic treatments for coronavirus disease 2019 (COVID-19): a review. JAMA 2020;323(18):1824-1836. DOI: 10.1001/jama.2020.6019.

4. Maggi E, Canonica GW, Moretta L. COVID-19: unanswered questions on immune response and pathogenesis. J Allergy Clin Immunol 2020;146(1):18-22. DOI:10.1016/j.jaci.2020.05.001 [J Allergy Clin Immunol 2020;146(5):1215].

5. Sinha P, Matthay MA, Calfee CS. Is a "cytokine storm" relevant to COVID-19? JAMA Intern Med 2020;180(9):1152-1154. DOI: 10.1001/ jamainternmed.2020.3313.

6. Coperchini F, Chiovato L, Croce L, Magri F, Rotondi M. The cytokine storm in COVID-19: an overview of the involvement of the chemokine/chemokine-receptor system. Cytokine Growth Factor Rev 2020;53:25-32. DOI: 10.1016/j.cytogfr.2020.05.003.

7. Li G, Fan Y, Lai Y, Han T, Li Z, Zhou P, et al. Coronavirus infections and immune responses. J Med Virol 2020;92(4):424-432. DOI: 10.1002/ jmv. 25685.

8. de Groot NG, Bontrop RE. COVID-19 pandemic: is a gender-defined dosage effect responsible for the high mortality rate among males? Immunogenetics 2020;72(5):275-277. DOI: 10.1007/s00251-02001165-7.

9. Akira S, Uematsu S, Takeuchi O. Pathogen recognition and innate immunity. Cell 2006;124(4):783-801. DOI: 10.1016/j. cell.2006.02.015.

10. Grimes JM, Grimes KV. p38 MAPK inhibition: a promising therapeutic approach for COVID-19. J Mol Cell Cardiol 2020;144:63-65. DOI: 10.1016/j.yjmcc.2020.05.007.

11. Coperchini F, Chiovato L, Croce L, Magri F, Rotondi M. The cytokine storm in COVID-19: An overview of the involvement of the chemokine/chemokine-receptor system. Cytokine Growth Factor Rev 2020;53:25-32. DOI: 10.1016/j.cytogfr.2020.05.003.

12. Moore JB, June $\mathrm{CH}$. Cytokine release syndrome in severe COVID-19. Science 2020;368(6490):473-474. DOI: 10.1126/science.abb8925.

13. RECOVERY Collaborative Group, Horby P, Lim WS, Emberson JR, Mafham M, Bell JL, Linsell L, et al. Dexamethasone in hospitalized patients with Covid-19 - preliminary report. N Engl J Med 2021;384(8):693-704. DOI: 10.1056/NEJMoa2021436.

14. Ucciferri C, Auricchio A, Di Nicola M, Potere N, Abbate A, Cipollone F, et al. Canakinumab in a subgroup of patients with COVID-19. Lancet Rheumatol 2020;2(8):E457. DOI: 10.1016/S2665-9913(20)30167-3.

15. Huet $T$, Beaussier H, Voisin O, Jouveshomme S, Dauriat G, Lazareth I, et al. Anakinra for severe forms of COVID-19: a cohort study. Lancet Rheumatol 2020;2(7):e393-e400. DOI: 10.1016/S26659913(20)30164-8.

16. Available from: https://emedicine.medscape.com/article/2500122overview\#a14 [Accessed on June 30, 2020]. 
17. Available from: https://www.medscape.com/answers/2500114197456/what-is-the-role-of-the-il-6-inhibitor-sarilumab-kevzarain-the-treatment-of-coronavirus-disease-2019-covid-19 [Accessed on June 30, 2020].

18. Omers EC, Eschenauer GA, Troost JP, Golob JL, Gandhi TN, Wang L, et al. Tocilizumab for treatment of mechanically ventilated patients with COVID-19. Clin Infect Dis 2021;73(2):e445-e454. DOI: 10.1093/cid/ciaa954.

19. F. Hoffmann-La Roche Ltd. Roche provides an update on the phase III COVACTA trial of Actemra/RoActemra in hospitalised patients with severe COVID-19 associated pneumonia (Press release). 2020. Available from: https://www.roche.com/dam/jcr:6d8de90d-2e3143c8-b4e1-0a24a2675015/en/29072020-mr-covacta.pdf.

20. Magro G. COVID-19: review on latest available drugs and therapies against SARS-CoV-2. Coagulation and inflammation cross-talking. Virus Res 2020;286:198070. DOI: 10.1016/j.virusres.2020.198070. PMID: 32569708; PMCID: PMC7305708.

21. Mehta Y, Dixit SB, Zirpe KG, Ansari AS. Cytokine storm in novel coronavirus disease (COVID-19): expert management considerations. Indian J Crit Care Med 2020;24(6):429-434. DOI: 10.5005/jp-journals-10071-23415.

22. Availablefrom:https://www.biocon.com/docs/Biocon_PR_Itolizumab_ Approved_for_Covid_India.pdf_[Accessed on July 30, 2020].

23. Nile SH, Nile A, Qiu J, Li L, Jia X, Kai G. COVID-19: pathogenesis, cytokine storm and therapeutic potential of interferons. Cytokine Growth Factor Rev 2020;53:66-70. DOI: 10.1016/j. cytogfr.2020.05.002.

24. Chinnaiyan AM, Huber-Lang M, Kumar-Sinha C, Barrette TR, ShankarSinha S, Sarma VJ, et al. Molecular signatures of sepsis: multiorgan gene expression profiles of systemic inflammation. Am J Pathol 2001;159(4):1199-1209. DOI: 10.1016/S0002-9440(10)62505-9.

25. Pandey RK, Sodhi A, Biswas SK, Dahiya Y, Dhillon MK. Mycobacterium indicus pranii mediates macrophage activation through TLR2 and NOD2 in a MyD88 dependent manner. Vaccine 2012;30(39):57485754. DOI: 10.1016/j.vaccine.2012.07.002.

26. Kumar P, Das G, Bhaskar S. Mycobacterium indicus pranii therapy induces tumor regression in MyD88- and TLR2-dependent manner. BMC Res Notes 2019;12(1):648. DOI: 10.1186/s13104-019-4679-0.

27. Desai NM, Khamar BM. Immunotherapy for tuberculous pericarditis. N Engl J Med 2014;371(26):2533-2534. DOI: 10.1056/ NEJMc1413185.

28. Power CA, Wei G, Bretscher PA. Mycobacterial dose defines the Th1/ Th2 nature of the immune response independently of whether immunization is administered by the intravenous, subcutaneous, or intradermal route. Infect Immun 1998;66(12):5743-5750. PMID: 9826349.

29. Ahmad F, Mani J, Kumar P, Haridas S, Upadhyay P, Bhaskar S. Activation of anti-tumor immune response and reduction of regulatory $T$ cells with Mycobacterium indicus pranii (MIP) therapy in tumor bearing mice. PLoS One 2011;6(9):e25424. DOI: 10.1371/journal.pone.0025424. PMID: 1984926; PMCID: PMC3184142.

30. Das S, Halder K, Goswami A, Chowdhury BP, Pal NK, Majumdar S. Immunomodulation in host-protective immune response against murine tuberculosis through regulation of the $T$ regulatory cell function. J Leukoc Biol 2015;98(5):827-836. DOI: 10.1189/jlb.3A0315114R. PMID: 26156009.

31. Kumar P, Tyagi R, Das G, Bhaskar S. Mycobacterium indicus pranii and Mycobacterium bovis BCG lead to differential macrophage activation in Toll-like receptor-dependent manner. Immunology 2014;143(2):258-268. DOI: 10.1111/imm.12306.

32. Spiegel M, Schneider K, Weber F, Weidmann M, Hufert FT. Interaction of severe acute respiratory syndrome associated coronavirus with dendritic cells. J Gen Virol 2006;87(Pt 7):1953-1960. DOI: 10.1099/ vir.0.81624-0.

33. Kumar P, John V, Marathe S, Das G, Bhaskar S. Mycobacterium indicus pranii induces dendritic cell activation, survival, and Th1/Th17 polarization potential in a TLR-dependent manner. J Leukoc Biol 2015;97(3):511-520. DOI: 10.1189/jlb.1A0714-361R.

34. Sharma P, Mukherjee R, Talwar GP, Sarathchandra KG, Walia R, Parida $\mathrm{SK}$, et al. Immunoprophylactic effects of the anti-leprosy Mw vaccine in household contacts of leprosy patients: clinical field trials with a follow up of 8-10 years. Lepr Rev 2005;76(2):127-143. PMID: 16038246.

35. Sharma P, Kar HK, Kaur H, Misra RS, Mukherjee A, Mukherjee R, Rani R. Induction of lepromin positivity and immunoprophylaxis in household contacts of multibacillary leprosy patients: a pilot study with a candidate vaccine, Mycobacterium w. Int J Lepr Other Mycobact Dis 2000;68(2):136-142. PMID: 11036493.

36. Lawan Y. Tuberculin conversion in HIV seropositives. J Indian Med Assoc 2002;100(10):622-623. PMID: 12452519.

37. Kharkar R. Immune recovery in HIV with Mycobacterium W. J Indian Med Assoc 2002;100(9):578-579. PMID: 12455393.

38. Sharma SK, Katoch K, Sarin R, Balambal R, Kumar Jain N, Patel N et al. Efficacy and safety of Mycobacterium indicus pranii as an adjunct therapy in category II pulmonary tuberculosis in a randomized trial. Sci Rep 2017;7(1):3354. DOI: 10.1038/s41598-017-03514-1.

39. De Lang A, Osterhaus AD, Haagmans BL. Interferon-gamma and interleukin-4 downregulate expression of the SARS coronavirus receptor ACE2 in Vero E6 cells. Virology 2006;353(2):474-481. DOI: 10.1016/j.virol.2006.06.011.

40. Prescribing Information. Sepsivac. Available from: URL: https:// www.cadilapharma.com/sepsivac-sepsis-saviour-cadila/ [Accessed on June 5, 2020].

41. Asiaed Collegium of Medical Education, DCCET, ISCCM Bangalore Chapter; 2020. p. 1-4.

42. Sehgal IS, Bhalla A, Puri GD, Yaddanapudi LN, Singh M, Malhotra P, et al. Safety of an immunomodulatory Mycobacterium w in COVID-19. Lung India 2020;37(3):279-281. DOI: 10.4103/lungindia.lungindia_242_20. 